\title{
Identification of hypertensive patients with dominant affective temperaments might improve the psychopathological and cardiovascular risk stratification: a pilot, case-control study
}

\author{
Andrea László ${ }^{1}$, Levente Babos ${ }^{1}$, Zsóka Kis-Igari ${ }^{1}$, Adrienn Pálfy ${ }^{1}$, Péter Torzsa ${ }^{1}$, Ajándék Eőry ${ }^{1}$, László Kalabay ${ }^{1}$, \\ Xenia Gonda ${ }^{2,3,4^{*}} \mathbb{D}$, Zoltán Rihmer ${ }^{3}$, Orsolya Cseprekál ${ }^{5}$, András Tislér ${ }^{5}$, Judit Hodrea ${ }^{6}$, Lilla Lénárt ${ }^{6}$, \\ Andrea Fekete ${ }^{6}$ and János Nemcsik ${ }^{1,7}$
}

\begin{abstract}
Background: Although mood disorders and cardiovascular diseases have widely studied psychosomatic connections, data concerning the influence of the psychopathologically important affective temperaments in hypertension are scarce. To define a possibly higher cardiovascular risk subpopulation we investigated in well-treated hypertensive patients with dominant affective temperaments (DOM) and in well-treated hypertensive patients without dominant temperaments the level of depression and anxiety, arterial stiffness and serum Brain-derived Neurotrophic Factor (seBDNF).

Methods: 175 hypertensive patients, free of the history of psychiatric diseases, completed the TEMPS-A, Beck Depression Inventory and Hamilton Anxiety Scale questionnaires in two primary care practices. Of those 175 patients, 24 DOM patients and 24 hypertensive controls (matched in age, sex and the presence of diabetes) were selected for measurements of arterial stiffness and seBDNF level.

Results: Beck and Hamilton scores in DOM patients were higher compared with controls. Pulse wave velocity and augmentation index did not differ between the groups while in the DOM patients decreased brachial systolic and diastolic and central diastolic blood pressures were found compared with controls. SeBDNF was lower in the DOM group than in the controls ( $22.4 \pm 7.2$ vs. $27.3 \pm 7.8 \mathrm{ng} / \mathrm{mL}, p<0.05)$.

Conclusions: Although similar arterial stiffness parameters were found in DOM patients, their increased depression and anxiety scores, the decreased brachial and central diastolic blood pressures as well as the decreased seBDNF might refer to their higher vulnerability regarding the development not only of major mood disorders, but also of cardiovascular complications. These data suggest that the evaluation of affective temperaments should get more attention both with regard to psychopathology and cardiovascular health management.
\end{abstract}

Keywords: Hypertension, Affective temperaments, Depression, Anxiety, Arterial stiffness, Brain-derived neurotrophic factor, Cardiovascular risk

\footnotetext{
*Correspondence: kendermagos@yahoo.com; gonda.xenia@med.

semmelweis-univ.hu

${ }^{4}$ MTA-SE Neurochemistry Research Group, Budapest, Hungary

Full list of author information is available at the end of the article
} 


\section{Background}

Mood disorders are common public health problem in the Western world and their strong connection to cardiovascular diseases (CVD) is well known [1]. Moreover, the negative impact of adverse individual psychological traits and characteristics, like anger, hostility and anxiety is also well-documented in connection to the development and progression of coronary heart disease $[2,3]$, while individual differences in antagonism-related traits seem to predict a variety of cardiovascular outcomes [4, 5].

There are multiple mechanisms by which depression could increase the probability of vascular diseases, such as increased platelet activation [6], inflammatory markers [7] as well as reduced heart rate variability [8]. Parallel to this, well-established biomarkers of inflammation were also found to be elevated in persons in states of anger or hostility $[9,10]$, while a reduced function of the autonomic nervous system was observed in states of anxiety [11] and interpersonal antagonism was connected with carotid arterial intima-media thickening [12].

Another possible link might be the brain-derived neurotrophic factor (BDNF), a member of the neurotrophic factor family, which is not only associated with major depressive disorder [13], but its higher serum level is also connected to a decreased risk of cardiovascular disease and mortality [14].

The independent continuous relationship between elevated blood pressure and several cardiovascular events is well-known for patients in all ages and ethnic groups [15]. Besides elevated blood pressure, arterial stiffening is increasingly recognised as a risk factor for CVD. The determination of decreased arterial elasticity helps to identify the patient's higher risk of cardiovascular morbidity and mortality [16]. In Europe, the measurement of arterial stiffness is already a recommended method for cardiovascular risk assessment among hypertensive patients [17]. Previously, depressive symptoms, especially in diagnosed depressive disorders were found to be associated with increased arterial stiffening [18].

According to our recent findings, specific affective temperament types (depressive, cyclothymic, hyperthymic, irritable and anxious) are the subclinical, trait-related manifestations and commonly the antecedents of minor and major mood disorders [19]. Recently, in a study of primary care patients we also demonstrated a strong connection between dominant cyclothymic temperament and hypertension [20]. Moreover, we also showed that cyclothymic temperament is connected to acute coronary events in hypertensive patients [21].

We hypothesised that hypertensive patients with dominant affective temperaments (DOM) score higher depression and anxiety values and have impaired arterial stiffness, central blood pressure or serum BDNF compared with hypertensive patients without dominant affective temperaments, forming a high-risk subgroup patient population.

\section{Methods \\ Patients}

In our cross-sectional case-control study well-treated chronic (>12 months medication) hypertensive Caucasian patients were investigated in two primary care practices. All patients completed the TEMPS-A, Beck Depression Inventory (BDI) and Hamilton Anxiety Scale (HAM-A) questionnaires in order to evaluate the presence of affective temperaments, depression and anxiety, respectively. Following this initial screening, patients with dominant affective temperaments (reaching the mean +2 SD point scores or higher in each affective temperament subscale, DOM) were identified. Hypertensive controls without DOM, matched in age, gender and presence of diabetes, were selected from the initial hypertensive patient cohort and included in the arterial stiffness and seBDNF measurements. As blood pressure medication can highly influence arterial stiffness, it was further analysed, but patients were not matched in this aspect.

Exclusion criteria were the history or ongoing treatment of depression or anxiety (as with arterial stiffening the associations are clarified [18]), and the presence of atrial fibrillation or uncontrolled hypertension (>145/95 $\mathrm{mmHg}$ in repeated office measurements). In patients with an average blood pressure between $140 / 90$ and $145 / 95 \mathrm{mmHg}$ in repeated office blood pressure measurements, ambulatory 24-h blood pressure monitoring or home blood pressure monitoring was performed and only well-controlled patients were admitted to the study. Prior to the participation, all patients gave their written informed consent. The study was approved by the Scientific and Research Ethics Committee of the Medical Research Council, Hungarian Ministry of Health (ETT TUKEB 842/PI/2011) and carried out in accordance with the tenets of the Declaration of Helsinki.

\section{Procedures}

During the initial visit patients completed the questionnaires. Physical examination (blood pressure, heart rate, height, weight and waist circumference) were completed and data on medical history (with special attention to cardiovascular risk factors, complications and depression) as well as on current medication was collected.

After the analysis of the questionnaires, patients meeting the criteria of dominant temperament and their controls were invited for arterial stiffness and seBDNF measurements, which took place within 1 month after the initial visit. 


\section{Questionnaires}

The temperament evaluation of Memphis Pisa, Paris and San Diego (TEMPS-A) questionnaire is an 110-item, self-report instrument, developed to measure affective temperaments on depressive, cyclothymic, hyperthymic, irritable and anxious subscales and requiring the answers 'yes' (score 1) or 'no' (score 0) [22]. TEMPS-A is used to assess the point scores of each subscale and also to measure the presence of the dominant form of affective temperaments by taking the mean of the subscale and adding up two standard deviations to it. Those reaching the mean +2 SD level or higher in each subscale are considered to have dominant affective temperaments.

The beck depression inventory (BDI), created by Aaron T. Beck, is a 21-question multiple-choice self-report questionnaire, one of the widely used instruments for measuring the severity of depression. Participants are asked to make ratings on a four-point scale, where a higher score correlates with more severe depression.

Hamilton Anxiety Scale (HAM-A) was evaluated by the examiner to study the severity of anxiety. The scale consists of 14 items, each item is scored on a scale of 0 (not present) to 4 (severe anxiety).

\section{Arterial stiffness recordings}

Measurements were performed in a temperature-controlled room in supine position, on the day of blood sampling, before it, between 7.00 and 8.00 a.m. Patients were required to fast overnight and refrain from smoking and caffeine-containing beverages before the procedure, but to take the usual blood pressure regulating medication. Upon arrival at the investigation unit, the subjects were equipped with measurement devices, and then rested in supine position for approximately $15 \mathrm{~min}$ before being measured. Arterial stiffness parameters were evaluated using the validated, gold-standard PulsePen tonometer (DiaTecne, Milan, Italy, [23]). With this method the pulse wave velocity (PWV) augmentation index (AI), as well as the central systolic blood pressure (central SBP) and central pulse pressure (central PP) can be calculated. In each subject two sequences of measurements were performed and their mean was used for statistical analysis. ECG was recorded continuously from the limb lead with the largest R wave.

In the PWV calculations $80 \%$ of the carotid-femoral distance was used, following the recent guideline [24]. Previously we evaluated the intra- and interobserver variabilities of PWV measurements obtained by the PulsePen device on hypertensive patients and found them to be 4.6 and $6.3 \%$ high, respectively. As PulsePen calculates pressure values using brachial diastolic blood pressure calibration, the calculated central and brachial diastolic blood pressure values were identical [23].

\section{Measurement of seBDNF concentration}

Peripheral blood samples of patients were collected in anticoagulant-free tubes, right after the measurement of arterial stiffness. After centrifugation $(3600 \mathrm{rpm}$ for $6 \mathrm{~min}$ ) the serum was stored at $-20{ }^{\circ} \mathrm{C}$. SeBDNF was measured using commercially available sandwich enzyme-linked immunosorbent assay ( $\& D$ Systems, Minneapolis MN, USA) according to the manufacturer's protocol and serum BDNF level was determined in $\mathrm{ng} /$ $\mathrm{mL}$.

\section{Data analysis}

Data were expressed as mean \pm SEM and medians. Differences in variables between controls and DOM patients were analysed using unpaired Student's $t$ tests or MannWhitney rank-sum tests for data failing tests of normality. Blood pressure medications were calculated and compared using equivalent doses, differences were analysed with unpaired Student's $t$ tests or Mann-Whitney rank-sum tests. Significance was accepted at $p<0.05$. Statistical analysis was performed using the SigmaStat for Windows Version 3.5 (SPSS) program package.

\section{Results and discussion \\ Characteristics of the patients}

183 hypertensive patients were recruited to participate in the study and 175 of them completed the questionnaires. 29 of the patients had dominant affective temperaments (DOM). Out of the 29 DOM patients one died 3 days prior to the planned arterial stiffness measurement and four declined to further participate in arterial stiffness measurements. The arterial stiffness and BDNF of altogether 48 hypertensive patients was evaluated: 24 DOM and 24 control subjects matched in age, gender and presence of diabetes.

Among the DOM patients six subjects with depressive, five irritable and four anxious dominant temperaments were found. In the other patients, combinations of dominant temperaments were present: three patients had cyclothymic and depressive, two had cyclothymic and irritable, two had cyclothymic, depressive and anxious, one had cyclothymic, irritable and anxious temperaments and one patient was dominant for cyclothymic, irritable, anxious and depressive affective temperaments. No patient with a dominant hyperthymic temperament was found in our cohort.

\section{Comparing the control and DOM patients for statistical differences}

Baseline demographic, anthropometric and laboratory parameters and the used cardiovascular medications of the patients are presented in Table 1. SeBDNF levels were lower in DOM patients. Compared with controls, beta-blockers 
Table 1 Baseline demographic, anthropometric and laboratory parameters and the used cardiovascular medication of the patients

\begin{tabular}{lll}
\hline & Control & DOM \\
\hline$N$ (male:female) & $24(9: 15)$ & $24(9: 15)$ \\
Age (year) & $63.7 \pm 2.54$ & $64.3 \pm 2.52$ \\
Body height (cm) & $164.5 \pm 1.51$ & $166 \pm 2.06$ \\
Body weight (kg) & $76.3 \pm 2.66$ & $81 \pm 3.34$ \\
AC (cm) & $101.5 \pm 4.1$ & $102 \pm 5.5$ \\
BMI (kg/m $\left.{ }^{2}\right)$ & $28.2(26-31.2)$ & $29.8(24.4-34.6)$ \\
Glucose $(\mathrm{mmol} / \mathrm{l})$ & $5.36(5.03-6.07)$ & $5.7(4.94-6.63)$ \\
CKD-EPI GFR (mmol/l) & $77.5(62.5-86)$ & $78.5(60.8-90)$ \\
Uric acid $(\mu \mathrm{mol} / \mathrm{l})$ & $309.3 \pm 15.26$ & $321.6 \pm 16.82$ \\
Cholesterol (mmol/l) & $5.48 \pm 0.22$ & $5 \pm 0.35$ \\
Triglyceride (mmol/l) & $1.36(1.08-2.18)$ & $1.82(0.99-2.15)$ \\
BDNF (ng/ml) & $27.29(24.2-30.35)$ & $20.10(14.74-27.11)^{*}$ \\
ACE-inhibitors [n (\%)] & $13(54.2)$ & $13(54.2)$ \\
ARBs & $9(37.5)$ & $5(20.8)$ \\
Calcium-channel blockers & $11(45.8)$ & $11(45.8)$ \\
Beta-blockers & $12(50)$ & $18(75)^{*}$ \\
Diuretics & $11(45.8)$ & $11(45.8)$ \\
Antiplatelet medication & $8(33.3)$ & $11(45.8)$ \\
\hline
\end{tabular}

The values are mean \pm SEM or medians (quartiles)

The groups were compared for differences by using Student's $t$ test or the Mann-Whitney rank-sum for data failing tests of normality

$D O M$ patients with dominant affective temperament, $A C$ abdominal circumference, $B M I$ body mass index, CKD-EPI GFR glomerular filtration rate assessed by the chronic kidney disease epidemiology collaboration glomerular filtration rate equation; BDNF: brain-derived neurotrophic factor, $A R B S$ angiotensin II receptor blockers

$* p<0.05$ compared with controls

were prescribed more frequently and in higher dose in the DOM group [0.63 (0-5) vs. $5(0.63-6.88) \mathrm{mg}$, calculated for bisoprolol, respectively, $p<0.05]$. No differences were found in the mean duration of hypertension among controls and DOM patients [10.5 (4-15.8) vs. 12 (6.5-17.8) $p=0.238$, respectively]. No differences were found among the groups studied in smoking habits and in the frequency of physical training (data are not shown).

Table 2 represents the differences in the five affective temperaments and in the BDI and HAM-A scores. Compared with controls, in DOM patients depressive, cyclothymic, irritable and anxious scores were higher, while hyperthymic scores were equal. Both BDI and HAM-A scores were markedly higher in DOM patients than in the controls.

Brachial and central hemodynamic and arterial stiffness parameters are shown in Table 3. Brachial systolic and both brachial and central diastolic and mean blood pressures were lower in DOM patients. PWV and AI, the two main arterial stiffness parameters, did not differ when compared with controls.
Table 2 TEMPS-A scores of affective temperaments, BDI and HAM-A scores

\begin{tabular}{lll}
\hline & $\begin{array}{l}\text { Control } \\
\mathbf{N = 2 4}\end{array}$ & $\begin{array}{l}\text { DOM } \\
\mathbf{N = 2 4}\end{array}$ \\
\hline Depressive & $6(4.25-8.75)$ & $12.5(7-13.75)^{*}$ \\
Cyclothymic & $3(1-5)$ & $9.5(7-13.75)^{*}$ \\
Hyperthymic & $12.13 \pm 0.73$ & $10.46 \pm 0.99$ \\
Irritable & $2(1-4.75)$ & $9.5(5-11)^{*}$ \\
Anxious & $5.08 \pm 0.81$ & $14.67 \pm 0.88^{*}$ \\
BDI & $5(2-7.75)$ & $14.5(8.5-19.75)^{*}$ \\
HAM-A & $7 \pm 1.27$ & $16.67 \pm 1.68^{*}$ \\
\hline
\end{tabular}

The values are mean \pm SEM and medians (quartiles). The groups were compared for differences by using Student's $t$ test or the Mann-Whitney rank-sum for data failing tests of normality

$D O M$ patients with dominant affective temperament, TEMPS-A the temperament evaluation of Memphis Pisa, Paris and San Diego questionnaire, $B D /$ beck depression inventory, HAM-A Hamilton Anxiety Scale

${ }^{*} p<0.05$ compared with controls

Table 3 Brachial and central hemodynamic and arterial stiffness parameters

\begin{tabular}{|c|c|c|}
\hline & $\begin{array}{l}\text { Control } \\
N=24\end{array}$ & $\begin{array}{l}\text { DOM } \\
N=24\end{array}$ \\
\hline $\mathrm{HR}(1 / \mathrm{min})$ & $66 \pm 1.25$ & $63.1 \pm 1.17$ \\
\hline SBPB (Hgmm) & $130.8(122-137.1)$ & $122.6(116.4-129.7)^{*}$ \\
\hline DBPB (Hgmm) & $71.2 \pm 1.5$ & $66.6 \pm 1.71^{*}$ \\
\hline MBPB (Hgmm) & $91.9 \pm 1.53$ & $86.6 \pm 1.94^{*}$ \\
\hline PPB (Hgmm) & $59.3(49.4-67.5)$ & $54.3(50.1-61.9)$ \\
\hline Central SBP (Hgmm) & $124.3(113.5-136.4)$ & $117(112.6-131.7)$ \\
\hline Central DBP (Hgmm) & $71.2 \pm 1.5$ & $66.5 \pm 1.71^{*}$ \\
\hline Central MBP (Hgmm) & $94.1 \pm 1.55$ & $88.9 \pm 1.96^{*}$ \\
\hline Central PP (Hgmm) & $50.6(44.5-66.6)$ & $52.3(48.8-1.72)$ \\
\hline $\mathrm{PWV}(\mathrm{m} / \mathrm{s})$ & $9.32(8.02-11.25)$ & $8.74(8.32-9.87)$ \\
\hline $\mathrm{Al}(\%)$ & $16.04 \pm 2.24$ & $14.54 \pm 2.66$ \\
\hline
\end{tabular}

The values are mean \pm SEM and medians (quartiles). The groups were compared for differences by using Student's t test or the Mann-Whitney rank-sum for data failing tests of normality

$D O M$ patients with dominant affective temperament, $H R$ heart rate, $S B P B$ systolic brachial blood pressure, $D B P B$ diastolic brachial blood pressure, $M B P B$ mean brachial blood pressure, $P P B$ brachial pulse pressure, Central SBP central systolic blood pressure, Central DBP central diastolic blood pressure, Central MBP central mean blood pressure, Central PP central pulse pressure, PWV pulse wave velocity, Al Augmentation index

${ }^{*} p<0.05$ compared with controls

Our pilot study was performed on hypertensive patients with dominant cyclothymic, irritable, depressive or anxious affective temperaments without the history or any present psychiatric medications. We found that DOM patients had higher anxiety and depression scores and lower seBDNF level. DOM patients had similar levels of arterial stiffening with a lower peripheral and central blood pressure compared with hypertensive controls. 


\section{Affective temperaments are associated with depression and anxiety}

Affective temperaments are tightly related to affective disorders. Hyperthymic temperament was found to be associated with type-I and cyclothymic with type-II bipolar disease [25] and atypical depression [19, 26], depressive temperament, in contrast to this, with unipolar major depression $[19,27]$. In our cohort DOM patients also had higher depression and anxiety scores suggesting the importance of a joint evaluation of affective temperaments together with depression and anxiety even in those hypertensive patients who have no records of previous psychiatric diseases or any present antidepressant or anxiolytic medication.

\section{Affective temperaments and cardiovascular risk}

Although the presence of dominant affective temperaments frequently precedes the onset of minor and major affective illness [19], and therefore screening for their presence would be an important target in the prevention and early intervention of cardiovascular disorders as well, only few studies are available which aim to investigate the role of affective temperaments in the development and risk of different cardiovascular diseases. Patients with depressive temperament were found to have worse metabolic control in type-2 diabetes [28], while cyclothymic, irritable and anxious temperaments showed affinity to obesity [29]. Recently we evaluated the role of affective temperaments in primary hypertension and found a significant association with the dominant cyclothymic temperament [20]. Moreover, cyclothymic temperament was associated with acute coronary events in hypertensive patient population [21]. In our present study, patients with affective temperaments had lower brachial and central diastolic and mean blood pressure values than controls. It is well known that decreased diastolic blood pressure is associated with increased mortality [30]. Parallel to our previous findings in hypertensive patients mentioned above [20,21], this phenomenon of decreased blood pressure values might be more expressed in cyclothymic patients and would in this case suggest their increased susceptibility to cardiovascular complications. However, the clarification of this hypothesis requires further studies.

As our DOM patients had higher depression score compared with control patients, one explanation of the decreased blood pressure might reflect the fact that lower blood pressure levels are often accompanied by a pronounced presence of depressive symptoms and in followup studies symptoms of anxiety and depression predicted the development of lower blood pressure [31, 32]. In case of a co-occurring onset of depression and hypotension, the pathophysiological mechanisms are considered to be the alterations in neurohormonal, immune and autonomic regulations [33]. Whether only the increased depression per se caused the decreased blood pressure in our DOM patients, or another independent factor is also involved, is a question still to be answered.

Most of the studies support the idea that antagonistic traits, depression and anxiety increase the probability of the development of cardiovascular diseases [12, 34, 35], and data are also available with respect to arterial stiffness. In their population-based, cross-sectional study including 3704 elderly patients, Tiermeier et al. found that patients with increased arterial stiffness were more likely to have depressive symptoms. The association was stronger in cases with diagnosed depressive disorders. The authors concluded that arterial stiffness may partly cause the proposed relationship between vascular factors and depression [18]. In contrast to this we found no difference in PWV or augmentation index between our DOM and control hypertensive patients. An explanation to this phenomenon can be that in the study of Tiermeier et al. the patients' arterial stiffness was much higher, as the border of the lowest PWV quartile was $11.4 \mathrm{~m} / \mathrm{s}$. This suggests a very poor vascular status of those patients, while in our patients PWV values were much lower.

In a recent study of Seldenrijk et al., depression and anxiety sensitivity and their association with arterial stiffening were evaluated. The authors found that out of these only anxiety sensitivity was associated with arterial stiffness; however, they studied only the augmentation index, which is a more variable parameter compared to PWV and is influenced by resistance vessels, that can be dysfunctional in patients with anxiety [36, 37]. It is also worth mentioning that the population of Seldenrijk et al. was much younger (46 years) compared with ours and only $18 \%$ of the patients regularly took antihypertensive medication which suggests their better general resistance vessel function. Considering all these results we suppose that in older patients besides optimal vascular therapy, the deleterious effects of depression and anxiety for arterial stiffening can be attenuated, but in younger population without vascular medication the deleterious effects of anxiety can lead to detectable dysfunction of resistance vessels in comparison to healthy controls.

\section{Serum BDNF level, affective temperaments and allostatic load}

In our study seBDNF, too, was measured and we observed its decreased level in our DOM patients. SeBDNF was found to be lower in patients suffering from major depressive disorder and some types of anxiety disorders, while in animal models the regulation of BDNF was suggested to contribute both to anxiety-like behaviour and hypertension [38-40]. BDNF was found 
to be decreased also in such pathological conditions as acute coronary syndrome and type 2 diabetes [41, 42]. Whether the decreased seBDNF in our hypertensive DOM patients is correlated with their higher depression and anxiety and bears any clinical relevance with respect to the cardiovascular outcome or not, further studies need to clarify.

The term "allostatic load" refers to a cumulative, multisystem view of the physiologic toll that is required for adaptation to stress. In mood disorders, especially in bipolar disorder allostatic load increases progressively as mood episodes occur over time [43]. Among many mediators, neurotrophic factors such as decreased level of BDNF indicates allostatic load [44]. Seeman et al. found in their longitudinal, community-based study that allostatic load may play a role in cardiovascular disorders [45] and there is evidence that reduction in allostatic load is associated with lower all-cause mortality, even in geriatric patients [46]. As affective temperaments are the subclinical manifestations of minor and major mood disorders and we found decreased BDNF level in patients with dominant temperaments, it can indicate an increased allostatic load among them, as well. According to this theory the increased cardiovascular risk could also be explained with the phenomenon of allostatic load.

In our study the depressive, cyclothymic, irritable and anxious temperaments or their combinations were investigated together. The neurobiological background of these temperaments seems to be at least partly common, as all were found to be associated with the 5-HTTLPR polymorphism of the serotonin transporter gene, namely the presence of the s allele, which is connected with decreased serotonin uptake of cells [47]. Moreover, the scales of depressive, anxious, cyclothymic and irritable temperaments were found to be closely associated in different populations suggesting real phenotypical connections beyond the similarities in the neurobiological background $[48,49]$. Whether the clustering of dominant temperaments has any pronounced clinical relevance above single dominant temperaments is another question to be answered.

\section{Risk stratification of hypertensive patients}

The calculation of total cardiovascular risk of hypertensive patients is a very important task of hypertension care [17]. Our results support the possibility that in the future the evaluation of affective temperaments might be the part of the risk stratification procedure of hypertensive patients as besides the obvious connection with mood disorders, the identification of DOM patients could determine a higher cardiovascular risk patient population as well.

\section{Limitations}

The main limitation of our study is the relatively low number of patients involved. Out of 183 invited hypertensive patients, the arterial stiffness parameters of only 24 subjects with dominant affective temperament and 24 controls were analysed. The low number of patients limits the generalisability of our data and type I and type II errors cannot be excluded. As the detailed analysis of the impact of unique dominant affective temperaments on arterial stiffness, central blood pressure or seBDNF require higher number of involved patients, we defined this study as a "pilot". Another limitation comes from the cross-sectional design of the study which precludes causal inference.

\section{Conclusions}

In conclusion, although arterial stiffness parameters did not differ between the DOM subgroup of well-treated hypertensive patients and their hypertensive controls, their higher depressive and anxious scores and lower seBDNF might reflect their higher susceptibility for cardiovascular complications. Furthermore, DOM patients might bear a higher risk, as they have lower brachial and central diastolic blood pressure values in comparison to patients without dominant temperaments. The clinical significance of our findings with respect to the cardiovascular outcome of these patients needs further examinations on higher number of patients involved, but the cumulating data suggest that the evaluation of affective temperaments might improve both psychopathological and cardiovascular risk stratification.

\section{Abbreviations \\ AC: abdominal circumference; Al: augmentation index; ARBs: angiotensin II receptor blockers; BDI: beck depression inventory; BDNF: brain-derived neurotrophic factor; BMI: body mass index; Central DBP: central diastolic blood pressure; Central MBP: central mean blood pressure; Central PP: central pulse pressure; Central SBP: central systolic blood pressure; CKD-EPI GFR: glomerular filtration rate assessed by the chronic kidney disease epidemiology collabora- tion glomerular filtration rate equation; DBPB: diastolic brachial blood pres- sure; DOM: patients with dominant affective temperament; HAM-A: Hamilton Anxiety Scale; HR: heart rate; MBPB: mean brachial blood pressure; PPB: brachial pulse pressure; PWV: pulse wave velocity; SBPB: systolic brachial blood pressure; seBDNF: serum brain-derived neurotrophic factor; TEMPS-A: the temperament evaluation of Memphis Pisa, Paris and San Diego questionnaire.}

\section{Authors' contributions}

AL participated by data collection and analysis, arterial stiffness measurement and by the composition of the paper. LB participated by arterial stiffness measuring. Zs K-I, AP, PT and AE participated by patient recruitment and data acquisition and management. LK participated by data analysis and the critical review of the manuscript. XG and ZR helped by conceiving and designing the study and by critically reviewing the manuscript. OC participated by the analysis of the pulse wave curves and in the training of the examiners of arterial stiffness. AT designed and supervised the arterial stiffness part of the study and helped with the writing of the manuscript. JH, LL and AF participated by laboratory measurements and contributed to writing the manuscript. JN planned and supervised the study, helped by patient recruitment and completed the manuscript. All authors read and approved the final manuscript. 


\section{Author details}

${ }^{1}$ Department of Family Medicine, Semmelweis University Budapest, Budapest, Hungary. ${ }^{2}$ Department of Pharmacodynamics, Semmelweis University Budapest, Budapest, Hungary. ${ }^{3}$ Department of Clinical and Theoretical Mental Health, Semmelweis University Budapest, Budapest, Hungary. ${ }^{4}$ MTA-SE Neurochemistry Research Group, Budapest, Hungary. ${ }^{5}$ Ist Department of Internal Medicine, Budapest, Hungary. ${ }^{6}$ MTA-SE "Lendület" Diabetes Research Group Budapest, Budapest, Hungary. ${ }^{7}$ Health Service of Zugló (ZESZ), Budapest, Hungary.

\section{Acknowledgements}

The authors acknowledge the contribution of Lászlóné Hárshegyi and Zoltánné Reisz, who helped by medically assisting the patients and by data acquisition. We also acknowledge the contribution of Oleg Pogrebnyak for his technical and linguistic support. Xenia Gonda is recipient of the János Bolyai Research Fellowship of the Hungarian Academy of Sciences. This study was supported by the Hungarian Society of Hypertension and by the "Lendület" Research Grant: LP008/2014.

\section{Competing interests}

Xenia Gonda is a recipient of the János Bolyai Research Fellowship of the Hungarian Academy of Sciences. This study was supported by the Hungarian Society of Hypertension and by the "Lendület" Research Grant: LP008/2014.

Received: 22 June 2015 Accepted: 14 October 2015

Published online: 26 October 2015

\section{References}

1. Penninx BW, Beekman AT, Honig A, Deeg DJ, Schoevers RA, van Eijk JT, van Tilburg W. Depression and cardiac mortality: results from a community-based longitudinal study. Arch Gen Psychiatry. 2001;58(3):221-7.

2. Smith TW, Ruiz JM. Psychosocial influences on the development and course of coronary heart disease: current status and implications for research and practice. J Consult Clin Psychol. 2002;70(3):548-68.

3. Suls J, Bunde J. Anger, anxiety, and depression as risk factors for cardiovascular disease: the problems and implications of overlapping affective dispositions. Psychol Bull. 2005;131(2):260-300.

4. Williams JE, Nieto FJ, Sanford CP, Couper DJ, Tyroler HA. The association between trait anger and incident stroke risk: the Atherosclerosis Risk in Communities (ARIC) Study. Stroke. 2002;33(1):13-9.

5. Chida Y, Steptoe A. The association of anger and hostility with future coronary heart disease: a meta-analytic review of prospective evidence. J Am Coll Cardiol. 2009;53(11):936-46.

6. Markovitz JH, Shuster JL, Chitwood WS, May RS, Tolbert LC. Platelet activation in depression and effects of sertraline treatment: an open-label study. Am J Psychiatry. 2000;157(6):1006-8

7. Miller GE, Stetler CA, Carney RM, Freedland KE, Banks WA. Clinical depression and inflammatory risk markers for coronary heart disease. Am J Cardiol. 2002;90(12):1279-83.

8. Carney RM, Saunders RD, Freedland KE, Stein P, Rich MW, Jaffe AS. Association of depression with reduced heart rate variability in coronary artery disease. Am J Cardiol. 1995;76(8):562-4.

9. Ridker PM, Morrow DA. C-reactive protein, inflammation, and coronary risk. Cardiol Clin. 2003;21(3):315-25.

10. Ridker PM, Rifai N, Stampfer MJ, Hennekens CH. Plasma concentration of interleukin- 6 and the risk of future myocardial infarction among apparently healthy men. Circulation. 2000;101(15):1767-72.

11. Martens EJ, Nyklicek I, Szabo BM, Kupper N. Depression and anxiety as predictors of heart rate variability after myocardial infarction. Psychol Med. 2008;38(3):375-83.

12. Sutin AR, Scuteri A, Lakatta EG, Tarasov KV, Ferrucci L, Costa PT Jr, Schlessinger D, Uda M, Terracciano A. Trait antagonism and the progression of arterial thickening: women with antagonistic traits have similar carotid arterial thickness as men. Hypertension. 2010;56(4):617-22.

13. Karege F, Bondolfi G, Gervasoni N, Schwald M, Aubry JM, Bertschy G. Low brain-derived neurotrophic factor (BDNF) levels in serum of depressed patients probably results from lowered platelet BDNF release unrelated to platelet reactivity. Biol Psychiatry. 2005;57(9):1068-72.
14. Kaess BM, Preis SR, Lieb W, Beiser AS, Yang Q, Chen TC, Hengstenberg C, Erdmann J, Schunkert H, Seshadri S, et al. Circulating brain-derived neurotrophic factor concentrations and the risk of cardiovascular disease in the community. J Am Heart Assoc. 2015;4(3):e001544.

15. Lewington S, Clarke R, Qizilbash N, Peto R, Collins R. Age-specific relevance of usual blood pressure to vascular mortality: a meta-analysis of individual data for one million adults in 61 prospective studies. Lancet. 2002;360(9349):1903-13.

16. Veerasamy M, Ford GA, Neely D, Bagnall A, Macgowan G, Das R, Kunadian V. Association of aging, arterial stiffness and cardiovascular disease: a review. Cardiol Rev. 2014;22:223-32.

17. Mancia G, Fagard R, Narkiewicz K, Redon J, Zanchetti A, Bohm M, Christiaens T, Cifkova R, De Backer G, Dominiczak A, et al. 2013 ESH/ESC guidelines for the management of arterial hypertension: the Task Force for the Management of Arterial Hypertension of the European Society of Hypertension (ESH) and of the European Society of Cardiology (ESC). Eur Heart J. 2013:34(28):2159-219.

18. Tiemeier H, Breteler MM, van Popele NM, Hofman A, Witteman JC. Latelife depression is associated with arterial stiffness: a population-based study. J Am Geriatr Soc. 2003;51(8):1105-10.

19. Rihmer Z, Akiskal KK, Rihmer A, Akiskal HS. Current research on affective temperaments. Curr Opin Psychiatry. 2010;23(1):12-8.

20. Eory A, Gonda X, Lang Z, Torzsa P, Kalman J Jr, Kalabay L, Rihmer Z. Personality and cardiovascular risk: association between hypertension and affective temperaments-a cross-sectional observational study in primary care settings. Eur J Gen Pract. 2014;20:247-52.

21. Eory A, Rozsa S, Torzsa P, Kalabay L, Gonda X, Rihmer Z. Affective temperaments contribute to cardiac complications in hypertension independently of depression. Psychother Psychosom. 2014;83(3):187-9.

22. Akiskal HS, Akiskal KK, Haykal RF, Manning JS, Connor PD. TEMPS-A: progress towards validation of a self-rated clinical version of the temperament evaluation of the Memphis, Pisa, Paris, and San Diego autoquestionnaire. J Affect Disord. 2005:85(1-2):3-16.

23. Salvi P, Lio G, Labat C, Ricci E, Pannier B, Benetos A. Validation of a new non-invasive portable tonometer for determining arterial pressure wave and pulse wave velocity: the PulsePen device. J Hypertens. 2004:22(12):2285-93.

24. Van Bortel LM, Laurent S, Boutouyrie P, Chowienczyk P, Cruickshank JK, De Backer T, Filipovsky J, Huybrechts S, Mattace-Raso FU, Protogerou AD et al. Expert consensus document on the measurement of aortic stiffness in daily practice using carotid-femoral pulse wave velocity. J Hypertens. 2012;30(3):445-8.

25. Hantouche EG, Akiskal HS, Lancrenon S, Allilaire JF, Sechter D, Azorin JM, Bourgeois M, Fraud JP, Chatenet-Duchene L. Systematic clinical methodology for validating bipolar-II disorder: data in mid-stream from a French national multi-site study (EPIDEP). J Affect Disord. 1998;50(2-3):163-73.

26. Perugi G, Toni C, Travierso MC, Akiskal HS. The role of cyclothymia in atypical depression: toward a data-based reconceptualization of the borderline-bipolar II connection. J Affect Disord. 2003;73(1-2):87-98,

27. Akiskal HS, Akiskal K, Allilaire JF, Azorin JM, Bourgeois ML, Sechter D, Fraud JP, Chatenet-Duchene L, Lancrenon S, Perugi G, et al. Validating affective temperaments in their subaffective and socially positive attributes: psychometric, clinical and familial data from a French national study. J Affect Disord. 2005;85(1-2):29-36.

28. Gois C, Barbosa A, Ferro A, Santos AL, Sousa F, Akiskal H, Akiskal K, Figueira $\mathrm{ML}$. The role of affective temperaments in metabolic control in patients with type 2 diabetes. J Affect Disord. 2011;134(1-3):52-8.

29. Amann B, Mergl R, Torrent C, Perugi G, Padberg F, El-Gjamal N, Laakmann G. Abnormal temperament in patients with morbid obesity seeking surgical treatment. J Affect Disord. 2009;118(1-3):155-60.

30. Staessen JA, Gasowski J, Wang JG, Thijs L, Den Hond E, Boissel JP, Coope J, Ekbom T, Gueyffier F, Liu L, et al. Risks of untreated and treated isolated systolic hypertension in the elderly: meta-analysis of outcome trials. Lancet. 2000;355(9207):865-72.

31. Kim BS, Bae JN, Cho MJ. Depressive symptoms in elderly adults with hypotension: different associations with positive and negative affect. J Affect Disord. 2010;127(1-3):359-64.

32. Hildrum B, Mykletun A, Holmen J, Dahl AA. Effect of anxiety and depression on blood pressure: 11-year longitudinal population study. $\mathrm{Br}$ Psychiatry. 2008;193(2):108-13. 
33. Grippo AJ. Mechanisms underlying altered mood and cardiovascular dysfunction: the value of neurobiological and behavioral research with animal models. Neurosci Biobehav Rev. 2009;33(2):171-80.

34. Boyle SH, Michalek JE, Suarez EC. Covariation of psychological attributes and incident coronary heart disease in US. Air Force veterans of the Vietnam war. Psychosom Med. 2006;68(6):844-50.

35. Roest AM, Martens EJ, Denollet J, de Jonge P. Prognostic association of anxiety post myocardial infarction with mortality and new cardiac events: a meta-analysis. Psychosom Med. 2010;72(6):563-9.

36. Seldenrijk A, van Hout HP, van Marwijk HW, de Groot E, Gort J, Rustemeijer C, Diamant M, Penninx BW. Sensitivity to depression or anxiety and subclinical cardiovascular disease. J Affect Disord. 2013;146(1):126-31.

37. Stillman AN, Moser DJ, Fiedorowicz J, Robinson HM, Haynes WG. Association of anxiety with resistance vessel dysfunction in human atherosclerosis. Psychosom Med. 2013;75(6):537-44.

38. Shimizu E, Hashimoto K, Okamura N, Koike K, Komatsu N, Kumakiri C, Nakazato M, Watanabe H, Shinoda N, Okada S, et al. Alterations of serum levels of brain-derived neurotrophic factor (BDNF) in depressed patients with or without antidepressants. Biol Psychiatry. 2003;54(1):70-5.

39. Suliman S, Hemmings SM, Seedat S. Brain-Derived Neurotrophic Factor (BDNF) protein levels in anxiety disorders: systematic review and metaregression analysis. Front Integr Neurosci. 2013;7:55.

40. Salim S, Asghar M, Taneja M, Hovatta I, Chugh G, Vollert C, Vu A. Potential contribution of oxidative stress and inflammation to anxiety and hypertension. Brain Res. 2011;1404:63-71.

41. Manni L, Nikolova V, Vyagova D, Chaldakov GN, Aloe L. Reduced plasma levels of NGF and BDNF in patients with acute coronary syndromes. Int J Cardiol. 2005;102(1):169-71.
42. Krabbe KS, Nielsen AR, Krogh-Madsen R, Plomgaard P, Rasmussen P, Erikstrup C, Fischer CP, Lindegaard B, Petersen AM, Taudorf S, et al. Brainderived neurotrophic factor (BDNF) and type 2 diabetes. Diabetologia. 2007:50(2):431-8

43. Vieta E, Popovic D, Rosa AR, Sole B, Grande I, Frey BN, Martinez-Aran A, Sanchez-Moreno J, Balanza-Martinez V, Tabares-Seisdedos R, et al. The clinical implications of cognitive impairment and allostatic load in bipolar disorder. Eur Psychiatr J Assoc Eur Psychiatr. 2013;28(1):21-9.

44. Schloesser RJ, Huang J, Klein PS, Manji HK. Cellular plasticity cascades in the pathophysiology and treatment of bipolar disorder. Neuropsychopharmacol Off Publ Am Coll Neuropsychopharmacol. 2008:33(1):110-33.

45. Seeman TE, Singer BH, Rowe JW, Horwitz RI, McEwen BS. Price of adaptation-allostatic load and its health consequences. MacArthur studies of successful aging. Arch Intern Med. 1997;157(19):2259-68.

46. Karlamangla AS, Singer BH, Seeman TE. Reduction in allostatic load in older adults is associated with lower all-cause mortality risk: MacArthur studies of successful aging. Psychosom Med. 2006;68(3):500-7.

47. Gonda X, Rihmer Z, ZsombokT, Bagdy G, Akiskal KK, Akiskal HS. The 5HTTLPR polymorphism of the serotonin transporter gene is associated with affective temperaments as measured by TEMPS-A. J Affect Disord. 2006;91(2-3):125-31.

48. Rozsa S, Rihmer Z, Gonda X, Szili I, Rihmer A, Ko N, Nemeth A, Pestality P, Bagdy $G$, Alhassoon $O$, et al. A study of affective temperaments in Hungary: internal consistency and concurrent validity of the TEMPS-A against the TCl and NEO-PI-R. J Affect Disord. 2008;106(1-2):45-53.

49. Bloink R, Brieger P, Akiskal HS, Marneros A. Factorial structure and internal consistency of the German TEMPS-A scale: validation against the NEO-FFI questionnaire. J Affect Disord. 2005;85(1-2):77-83.

\section{Submit your next manuscript to BioMed Central and take full advantage of:}

- Convenient online submission

- Thorough peer review

- No space constraints or color figure charges

- Immediate publication on acceptance

- Inclusion in PubMed, CAS, Scopus and Google Scholar

- Research which is freely available for redistribution

Submit your manuscript at

www.biomedcentral.com/submit

C Biomed Central 